\title{
The importance of effectively combating HIV/AIDS through tackling the social aspects of the pandemic post-2015
}

\section{An open letter to Ban Ki Moon}

Winner

Medical student category

\section{Mr Secretary General:}

This letter starts with one patient.

I met her on my second day at Kenyatta National Hospital, on the paediatrics ward. I would like to tell you her name, but she had never been given one, so I called her "Beautiful". She was 3 months old and had never left the hospital. Twenty-four hours after a traumatic birth to an HIV-positive mother who had not accessed the care freely available to all pregnant women for prevention of mother-to-childtransmission, she had been abandoned. Despite having no name, she already had a status: positive. When I met her she didn't cry, because in her short life she had learnt that no one came when she did. She was developmentally delayed because, in such an underresourced department, caring for the well child was not the physician's priority. "What makes a mother give up her child?" I asked one of the junior doctors. He responded: "It happens; there are usually more of them". I explained that I didn't understand, and the doctor's response was as sharp as the answer was obvious - I was right. I didn't understand. "Having HIV is more than just a disease here", he said, "it is a lifetime of struggling against prejudice. It is a life sentence".

I knew the proportion of AIDS-related fatalities had decreased dramatically with the upscaling of highly active antiretroviral therapy (HAART) availability. ${ }^{1}$ In Kenya, where 300000 children are HIV positive, ${ }^{2}$ this little girl was my first insight into the social issues involved in the pandemic; unfortunately she wasn't going to be my last. During my elective I was involved in the daily diagnosis and management of many HIVpositive children. I saw at first hand the reluctance of caregivers to permit HIV testing, diagnosis and treatment for their children, and there was a significant loss to follow-up. It is estimated that for each paediatric HIV/AIDS case reported in Kenya there are 3-4 other infected children undiagnosed. ${ }^{3}$ Beautiful's situation forced me to confront the staggering social and cultural barriers to combating HIV/AIDS in some of the world's worst-affected countries.

The fight to achieve Millenium Development Goal 6 with regard to HIV/AIDS (achieve universal access to treatment by 2010 and begin to reverse its spread by 2015) has champions from doctors to musicians and has achieved falling infection rates and increasing availability of HAART. However, given the plight of Beautiful, and countless children like her,

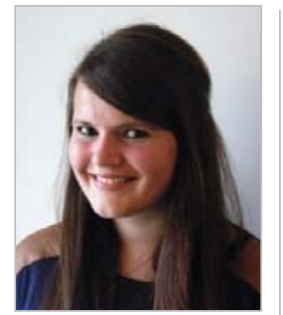

Heather Kitt $\mathrm{BSc}, \mathrm{MBBCh} B A \mathrm{O}$ Student

School of Medicine, Queen's University Belfast, Belfast, Northern Ireland, UK

heatherkitt@gmail.com

doi: 10.5694/mjal4.00830
I have come to believe that a paradigm shift in our approach to providing prophylaxis and treatment is desperately needed. In order to achieve the AIDS-free generation that UNICEF deems possible, the interplay of stigma, socioeconomic status and a distrust of health care professionals has to be better understood and addressed. As physicians and policymakers, to successfully tackle the epidemic affecting not only Kenya's children, but the world's, we need to see past the disease and consider the dramatic effect such a diagnosis can have on a patient and his or her family.

I spent 3 weeks in Kibera (Nairobi's biggest slum), where it is estimated that between $10 \%$ and $25 \% 4$ of children are HIV positive. The poorest neighbourhoods lack the necessary infrastructure to combat the spread of HIV. I met young girls, orphans of the pandemic, who had dropped out of school and had no other means to survive but through transactional sex work, resulting in pregnancy, poor health and HIV infection. ${ }^{5}$ One 14-year-old girl said she didn't see the point of condoms; she was going to die of AIDS anyway. The brutal truth is that statistics bear out this young girl's dark prediction. In homeless youth, HIV infection progresses rapidly to disease, and mortality is greater than $50 \%$ by 15 years of age. ${ }^{6}$ I met this girl while I was working in a free clinic serving the slum. Clearly, access to health care wasn't the issue.

During my time on the ward, Beautiful did not require anything more than her daily feed, something that the health care workers were only too ready to provide. But for the boy in the next cot it was different. He was also HIV positive and had been admitted for treatment of an AIDS-associated infection, which necessitated frequent blood tests. Not one of the ward staff were prepared to carry these out. So I did.

One study found $9 \%$ of doctors routinely refused treatment to HIV-positive patients or their children, considering it a waste of resources. ${ }^{7}$ When I read this statistic, I was ashamed to be part of the same profession that turned away people in so much need. I cannot imagine how devastating this must be for patients who simply have to live with the implications of their doctor's prejudice.

I was shocked that prejudice against those with HIV was reflected in health policy. Comprehensive Care Clinics (CCC) seemed like an unnecessary segregation of HIV sufferers. In Kenya the CCC's only function is to maintain the care of HIV-positive patients, and they are held in specific locations at specific times for 
only this purpose. ${ }^{8,9}$ Consequently, mothers do not bring their children, since their HIV status would be disclosed by simply attending. ${ }^{10}$ One mother told me "I am so afraid my neighbours will see me and they will know", such is the stigma surrounding HIV. This fear translates to antenatal clinics, where up to $16 \%$ of women refuse HIV testing ${ }^{11}$ and $36 \%$ do not return for the results. ${ }^{12}$ Likewise, $30 \%$ of HIVpositive breastfeeding mothers go against medical breastfeeding advice so as not to disclose their HIV status. $^{13,14}$

Yet, pioneering initiatives are breaking down these barriers. For instance, the results of a study being conducted at Kenyatta, centred around encouraging parents to disclose their own status and that of their child to trusted friends and family members, thus far indicate a positive correlation between disclosure and compliance with medical advice and treatment. In debunking this culture of secrecy, investigators are seeking to promote family-centred HIV care. ${ }^{15}$ The international community should look to these examples, building on their founding principles; to beat AIDS we must do more than diagnose and treat. This is what effective global health should look like post-2015.

I left Kenya and Beautiful in August, having contacted a charity-run orphanage and asked them to give her a home. When I had first arrived at the Kenyatta National Hospital I saw a straightforward choice for patients when given access to free medical treatment: say yes. What I learned was to see the devastation of the disease from the patients' perspective. To me the devastation was in high viral load, but to them it meant ostracism, poverty and prejudice. Their diagnosis meant no quality of life. And there is no point in having a treatment if those who need it don't access it. What I learnt is not only applicable in Kenya: the time I spent there opened my eyes to the challenging and unyielding nature of practising medicine in resource-poor settings.

Global health as a discipline has something to heed from this lesson as well. HIV treatment services fall short in the provision of care, not because of resources, but because they only focus on the biological aspects of HIV and not the impact such a diagnosis has upon the lives of the patients and their families. The post-2015 agenda should build on the valuable foundations of Millenium Development Goal 6 - the aspiration to reverse the spread of HIV/AIDS and provide universal treatment. However, in seeking to improve the lives of affected populations and countries we must be sure to consider HIV holistically rather than just biologically.

Mr Secretary General, I implore you, renew your commitment to the fight against HIV/AIDS, but this time deal with the social and cultural barriers to accessing treatment. In this way we must work together to ensure that no more children, like

Beautiful, are left nameless.

Sincerely,

Heather Kitt

1 Ross MJ, Klotman PE. HIV-associated nephropathy. AIDS 2004; 18 1089-1099.
To me the devastation was in high viral load, but to them it meant ostracism, poverty and prejudice
2 Kenya Ministry of Health. Kenya AIDS Indicator Survey 2007. Nairobi: Kenya Ministry of Health, 2009.

3 Lindegren ML, Steinberg S, Byers RH Jr. Epidemiology of HIV/AIDS in children. Pediatr Clin North Am 2000; 47: 1-20.

4 UNFPA, United Nations Population Fund. Urbanization: a majority in cities. New York: UNFPA, 2007. http://www.unfpa.org/pds/urbanization. htm (accessed Sep 2014).

5 Lopman B, Lewis J, Nyamukapa C, et al. HIV incidence and poverty in Manicaland, Zimbabwe: is HIV becoming a disease of the poor? AIDS 2007; 21 Suppl 7: S57-S66.

6 Prendergast A, Tudor-Williams G, Jeena P, Burchett S. International perspectives, progress, and future challenges of paediatric HIV infection. Lancet 2007; 370: 68-80.

7 Reis C, Heisler M, Amowitz LL, et al. Discriminatory attitudes and practices by health workers toward patients with HIV/AIDS in Nigeria. PLOS Med 2005; 2: e246.

8 De Baets AJ, Bulterys M, Abrams EJ, et al. Care and treatment of HIVinfected children in Africa: issues and challenges at the district hospital level. Pediatr Infect Dis J 2007; 26: 163-173.

9 McEvoy M. Culture and spirituality as an integrated concept in pediatric care. MCN Am J Matern Child Nurs 2003; 28: 39-43.

10 Wachira J, Middlestadt SE, Vreeman R, Braitstein P. Factors underlying taking a child to HIV care: implications for reducing loss to follow-up among HIV-infected and -exposed children. SAHARA J 2012; 9: 20-29.

11 Turan JM, Bukusi EA, Onono M, et al. HIV/AIDS stigma and refusal of HIV testing among pregnant women in rural Kenya: results from the MAMAS Study. AIDS Behav 2011; 15: 1111-1120.

12 Kiarie J, Nduati R, Koigi K, et al. HIV-1 testing in pregnancy: acceptability and correlates of return for test results. AIDS 2010; 14: 1468-1470.

13 National Department of Health. South African Demographic and Health Survey. 2008. http://www.gov.za/documents/detail.php?cid=170968 (accessed Sep 2014).

14 Matovu A, Kirunda B, Rugamba-Kabagambe G, et al. Factors influencing adherence to exclusive breast feeding among HIV positive mothers in Kabarole District, Uganda. East Afr Med J 2008; 85: 162-170.

15 Tonwe-Gold B, Ekouevi DK, Bosse CA, et al. Implementing family-focused HIV care and treatment: the first 2 years' experience of the mother-tochild transmission-plus program in Abidjan, Côte d'Ivoire. Trop Med Int Health 2009; 14: 204-212. 